\title{
Stomatal, mesophyll and biochemical limitations to soil drought and rewatering in relation to intrinsic water-use efficiency in Manchurian ash and Mongolian oak
}

\author{
K. ZHU, ${ }^{*, * *}$, F.H. YUAN ${ }^{*}$, A.Z. WANG ${ }^{*,+}$, J.B. WU*, D.X. GUAN",+, C.J. JIN*, J. FLEXAS ${ }^{* * *}$, \\ C.J. GONG ${ }^{* * * *}$, H.X. ZHANG ${ }^{*, * *}$, and Y.S ZHANG ${ }^{*}$
}

Key Laboratory of Forest Ecology and Management, Institute of Applied Ecology, Chinese Academy of Sciences, 110016 Shenyang, China*

University of Chinese Academy of Sciences, 100049 Beijing, China**

Research Group on Plant Biology under Mediterranean Conditions, Department of Biology of the University

of the Balearic Islands, Institute of Agroecology and Water Economy (INAGEA), Carretera de Valldemossa Km 7.5, 07122, Palma de Mallorca, Illes Balears, Spain ${ }^{* * *}$

The Institute of Atmospheric Environment, China Meteorological Administration, 110166 Shenyang, China

\begin{abstract}
The balance between stomatal and mesophyll conductance has been reported to directly influence intrinsic water-use efficiency $\left(\mathrm{WUE}_{\mathrm{i}}\right)$, but it is unclear whether variations in stomatal and mesophyll limitations $\left(l_{\mathrm{sc}}\right.$ and $l_{\mathrm{m}}$, respectively) affect $\mathrm{WUE}_{\mathrm{i}}$ during soil drought and rewatering. Limitations $\left(l_{\mathrm{sc}}, l_{\mathrm{m}}\right.$ and biochemical limitation, $\left.l_{\mathrm{b}}\right)$ and WUE $\mathrm{E}_{\mathrm{i}}$ were measured in Manchurian ash (Fraxinus mandshurica Rupr.) and Mongolian oak (Quercus mongolica Fish. ex Ledeb) saplings exposed to two levels of water stress (moderate and severe) and rewatering in this study. The primary limiting factors for photosynthesis among $l_{\mathrm{sc}}, l_{\mathrm{m}}$, and $l_{\mathrm{b}}$ and their correlations with WUE $\mathrm{E}_{\mathrm{i}}$ were assessed. Both $l_{\mathrm{sc}}$ and $l_{\mathrm{m}}$ increased with water stress, while $l_{\mathrm{b}}$ decreased, and during recovery, $l_{\mathrm{sc}}$ and $l_{\mathrm{m}}$ decreased, while $l_{\mathrm{b}}$ increased. Photosynthesis limitations directly influenced $\mathrm{WUE}_{\mathrm{i}}$, with $\mathrm{WUE}_{\mathrm{i}}$ being larger after rewatering than during water stress, increasing as biochemical capacity weakened at the expense of diffusional limitations $\left(l_{\mathrm{sc}}\right.$ and $\left.l_{\mathrm{m}}\right)$. Stomatal closure was more limiting to net photosynthesis in Mongolian oak than in Manchurian ash during the drought and recovery treatments; consistently higher $\mathrm{WUE}_{\mathrm{i}}$ was measured in the former species, possibly due to a more developed root system and larger leaf hydraulic conductance and stem vessel diameter in the former species.
\end{abstract}

Keywords: biochemical capacity; diffusional limitations; intrinsic water-use efficiency; rewatering; soil drought.

\section{Highlights}

- Both stomatal limitation $\left(l_{\mathrm{sc}}\right)$ and mesophyll limitation $\left(l_{\mathrm{m}}\right)$ increased with water stress, while biochemical limitation $\left(l_{\mathrm{b}}\right)$ decreased

- During recovery, $l_{\mathrm{sc}}$ and $l_{\mathrm{m}}$ decreased, while $l_{\mathrm{b}}$ increased

- Photosynthesis limitations directly influenced $\mathrm{WUE}_{\mathrm{i}}$
Received 27 July 2020

Accepted 21 December 2020

Published online 18 January 2021

${ }^{+}$Corresponding author

e-mail:waz@iae.ac.cn (A.Z. WANG) dxguan@iae.ac.cn (D.X.GUAN)

Abbreviations: $C_{\mathrm{i}}-$ intercellular $\mathrm{CO}_{2}$ concentration; $C_{\mathrm{c}}-$ chloroplast $\mathrm{CO}_{2}$ concentration; $D_{\text {stem }}-$ stem vessel diameter; ETR - electron transport rate; $\mathrm{F}_{\mathrm{m}}{ }^{\prime}$ - maximum fluorescence; $\mathrm{F}_{\mathrm{s}}$ - steady-state fluorescence; $g_{\mathrm{m}}$ - mesophyll conductance; $g_{\mathrm{sc}}$ - stomatal conductance to $\mathrm{CO}_{2} ; g_{\mathrm{sw}}$ - stomatal conductance to water; $K_{\text {leaf }}$ - hydraulic conductance; $l_{\mathrm{b}}$ - biochemical limitation; $l_{\mathrm{m}}-$ mesophyll limitation; $l_{\mathrm{sc}}-$ stomatal limitation; $P_{\mathrm{N}}$ - net photosynthetic rate; RWC - relative soil water content; SWC - soil water content; $S_{\mathrm{L}}, M C_{\mathrm{L}}$, and $B_{\mathrm{L}}$ - the contributions of $g_{\mathrm{sc}}, g_{\mathrm{m}}$, and biochemical capacity to $\mathrm{d} P_{\mathrm{N}} / P_{\mathrm{N}} ; R_{\mathrm{d}}-$ the mitochondrial respiration in the light; $V_{\mathrm{cmax}}-$ maximum carboxylation rate; $\mathrm{WUE}_{\mathrm{i}}$ - intrinsic water-use efficiency; $\alpha$ - the total leaf absorptance; $\beta$ - the partitioning of absorbed quantum between PSI and PSII; $\Gamma^{*}-\mathrm{CO}_{2}$-compensation point in the absence of respiration; $\Phi_{\mathrm{CO} 2}-$ the quantum efficiency of $\mathrm{CO}_{2}$ fixation; $\Phi_{\mathrm{PSII}}$ - the actual photochemical efficiency of photosystem II; $\Psi_{\mathrm{pd}}$ - predawn leaf water potential.

Acknowledgements: We thank the supports and technical assistance from the research group of Eco-climatology, Institute of Applied Ecology, CAS. This work was supported by the National Natural Science Foundation of China (41675112, 31670707, 31770755, 31400541).

Conflict of interest: The authors declare that they have no conflict of interest. 


\section{Introduction}

With the rapid climate change during recent decades, global precipitation distributions have become seriously unbalanced (Dore 2005, IPCC 2013). Consequently, soil drought events have become more frequent, longer, and more intense in some areas around the world, with profound consequences for ecosystems (Tezara et al. 1999). Soil water availability is the principal environmental factor affecting plant photosynthesis, growth, and primary production globally (Nemani et al. 2003, Zhou et al. 2014). In $\mathrm{C}_{3}$ photosynthesis, $\mathrm{CO}_{2}$ diffuses from the air surrounding the leaf to the sites of fixation within the chloroplasts (Flexas et al. 2018). This process is greatly affected by changes in stomatal $\left(g_{\mathrm{sc}}\right)$ and mesophyll conductances $\left(g_{\mathrm{m}}\right)$ and biochemical capacity, as reflected by parameters such as leaf maximum carboxylation and enzyme activity (Luterbacher et al. 2004, Flexas et al. 2006, Joos and Spahni 2008, Perez-Martin et al. 2011, Xiong et al. 2015a). The contributions of diffusional conductance to $\mathrm{CO}_{2}$ (i.e., $g_{\mathrm{sc}}$ and $g_{\mathrm{m}}$ ) and biochemistry to net photosynthetic rate $\left(P_{\mathrm{N}}\right)$ may be described in terms of relative limitations to $P_{\mathrm{N}}$, namely, stomatal limitation $\left(l_{\mathrm{sc}}\right)$, mesophyll limitation $\left(l_{\mathrm{m}}\right)$, and biochemical limitation $\left(l_{\mathrm{b}}\right)$ (Chaves 1991, Lawlor 1995, Cornic and Massacci 1996, Grassi and Magnani 2005, Flexas et al. 2009), which are severely influenced by soil drought.

During the past few decades, many efforts have been made to explore the changes in $l_{\mathrm{sc}}, l_{\mathrm{m}}$, and $l_{\mathrm{b}}$ during soil drought and their primary roles in photosynthesis (Flexas et al. 2002, Grassi and Magnani 2005, Cai et al. 2010, Aranda et al. 2012a, Rho et al. 2012). For instance, reductions in both $g_{\mathrm{sc}}$ and $g_{\mathrm{m}}$ have been found to account for most of the photosynthesis decrease under moderate water stress conditions, whereas photosynthesis has been found to be affected mainly by biochemical capacity (i.e., metabolic impairment) only under severe stress conditions (Nadal and Flexas 2019). Recently, a few studies have explored the responses of photosynthesis limitations. For example, in response to both water stress and rewatering, congeneric species have been found to exhibit contrasting responses linked to differences in tolerance to water stress (Cano et al. 2014). Furthermore, in a study of species in the Balearic Islands, Galmés et al. (2007) found that $l_{\mathrm{m}}$ was the strongest factor influencing photosynthesis recovery, whereas $l_{\mathrm{sc}}$ and $l_{\mathrm{b}}$ were of similar magnitudes throughout the entire range. Similarly, Cai et al. (2015) emphasized the primary role of $l_{\mathrm{m}}$ in the photosynthesis of $R$. delavayi during water stress and recovery. In addition, a dominant role of $l_{\mathrm{sc}}$ in photosynthesis had been suggested in studies by Flexas et al. (2009) and PerezMartin et al. (2014). Ennahli and Earl (2005) confirmed the important contribution of photosynthesis biochemistry to relative photosynthesis limitations. Additionally, Warren et al. (2011) found that the complete recovery of net photosynthesis after rewatering in several tree species was associated with a lower $\mathrm{CO}_{2}$ concentration in the chloroplasts $\left(C_{\mathrm{c}}\right)$ than the concentration observed in control plants, suggesting that water stress leads to increased amounts and/or activity of Rubisco (i.e., photosynthesis capacity). Furthermore, Grassi and Magnani (2005), Cano et al. (2013), and Peguero-Pina et al. (2018a) asserted that diffusive limitations (i.e., $l_{\mathrm{sc}}+l_{\mathrm{m}}$ ) strongly affect light-saturated assimilation and that $l_{\mathrm{b}}$ is quantitatively important only during leaf development and senescence. Nevertheless, the responses of $l_{\mathrm{sc}}, l_{\mathrm{m}}$, and $l_{\mathrm{b}}$ and their primary roles in photosynthesis during soil recovery and drought acclimation have been less well studied than those during drought, especially in the Changbai Mountains, Northeast China.

Previous studies have revealed that leaf water-use efficiency reflects the relationship between water consumption and carbon assimilation, and it has been widely used to assess plant adaption to water stress (Flexas et al. 2013, Xia et al. 2017, Pirzad and Mohammadzadeh 2018). Leaf intrinsic water-use efficiency $\left(\mathrm{WUE}_{\mathrm{i}}\right)$ greatly influences photosynthesis and strongly correlates with $\mathrm{CO}_{2}$ diffusion (Tomás et al. 2014, Barbour and Kaiser 2016). The balance between $g_{\mathrm{m}}$ and $g_{\mathrm{sc}}$ has been reported to influence directly leaf $\mathrm{WUE}_{\mathrm{i}}$ and gas-exchange recovery (Duan et al. 2010, Flexas et al. 2013, Cano et al. 2014), but the relationship regarding photosynthesis limitation with $\mathrm{WUE}_{\mathrm{i}}$ is unclear.

Manchurian ash (Fraxinus mandshurica Rupr.) and Mongolian oak (Quercus mongolica Fish. ex Ledeb) are two dominant tree species in the primitive broad-leaved Korean pine forests of northeast China. The two species exhibit contrasting drought tolerances; Mongolian oak has much stronger drought-tolerance capacity due to its more developed root system than that of Manchurian ash (Aranda et al. 2012b). We previously showed (Zhu et al. 2019) that upon rewatering Manchurian ash and Mongolian oak after different degrees of water stress, $g_{\text {sc }}$ and $g_{\mathrm{m}}$ recovered only partially in a species- and stress intensity-dependent manner. Here, we aimed to assess whether variation in $l_{\mathrm{sc}}$ and $l_{\mathrm{m}}$ during soil drought and rewatering in the two species result in variation in $\mathrm{WUE}_{\mathrm{i}}$. To address this question, the values of $l_{\mathrm{sc}}, l_{\mathrm{m}}$, and $l_{\mathrm{b}}$ and leaf $\mathrm{WUE}_{\mathrm{i}}$ during soil drought and rewatering were measured in Manchurian ash and Mongolian oak saplings. This study enhances our understanding of the drought-tolerance mechanisms of trees and the relationships of $g_{\mathrm{m}}$ and $g_{\mathrm{sc}}$ with leaf water-use efficiency.

\section{Materials and methods}

Plant material: Two dominant broad-leaved tree species of Manchurian ash (Fraxinus mandshurica Rupr.) and Mongolian oak (Quercus mongolica Fish. ex Ledeb) in a primitive broad-leaved Korean pine forest in the Changbai Mountains, Northeast China $\left(42^{\circ} 24^{\prime} \mathrm{N}, 128^{\circ} 06^{\prime} \mathrm{E}, 738 \mathrm{~m}\right.$ a.s.1.) were selected. The region has a typical temperate continental monsoon climate, a mean annual air temperature of $3.6^{\circ} \mathrm{C}$ and an average annual precipitation of $695 \mathrm{~mm}$. In April 2015, five-year-old saplings of both species with similar growth status collected from a primitive broad-leaved Korean pine forest in the Changbai Mountains of Northeast China were transplanted into individual pots, each with a volume of $29.28 \mathrm{~L}(30.0 \mathrm{~cm}$ 
height, $34.3 \mathrm{~cm}$ diameter) and containing $27 \mathrm{~L}$ of surface soil collected from the same forest from which the saplings were collected, with a field moisture capacity (FC) of $0.426 \mathrm{~g} \mathrm{~cm}^{-3}$.

Experimental design: Potted saplings were proportionally divided into three groups subjected to three treatments, with five replicates per treatment: well irrigated (control, $\mathrm{CK}, 90 \pm 5 \% \mathrm{FC}$ ), moderate water stress (MW, $40 \pm 5 \%$ $\mathrm{FC}$ ), and severe water stress (SW, $20 \pm 5 \% \mathrm{FC}$ ). Before starting the water control experiment, the potted saplings were well irrigated daily from 20 May to 20 June to FC. Then, the water-stressed saplings were allowed to dry naturally without water input while the controls were well irrigated for the next $10 \mathrm{~d}$. Soil water content (SWC, volumetric water content) at a $15-\mathrm{cm}$ depth was monitored every 30 min using a soil humidity real-time observation system (93640 Hydra, Stevens, USA). SWC was converted to relative $\mathrm{SWC}$ (relative soil water content - RWC; $\mathrm{RWC}=\mathrm{SWC} / \mathrm{FC} \times 100 \%)$ to describe the variation in $\mathrm{SWC}$ in the pots. When RWC declined to the designated stress levels, the water control experiment was started. During the experiment, all saplings were watered (not every day) according to the real-time RWC obtained from the 93640 Hydra system to maintain their designated water stress or non-stress status. In addition, five replicate plants per treatment were used for gas-exchange measurements in this study, and all measurements for the control, waterstressed, and rewatered saplings were collected within $3 \mathrm{~d}$. Specifically, the measurements were conducted after $2 \mathrm{~d}$ of rewatering, and the plants were well watered during the recovery period.

The saplings were blocked from outside water by placing pedestals under the pots. In addition, all potted saplings were placed under a 10-m long, 5-m wide, and $3.5-\mathrm{m}$ high rain shelter covered with transparent plastic film (95\% light transmittance) that was well ventilated with open sidewalls. The variations in daily soil RWC during soil drought and rewatering are shown in Fig. 1.

Predawn leaf water potential: To reflect soil moisture stress, we measured predawn leaf water potential $\left(\Psi_{\mathrm{pd}}\right.$ $[\mathrm{MPa}])$ in three different leaves per treatment using a pressure chamber (1505D, PMS Instrument Company, USA). The detailed measurement processes are described in Zhu et al. (2019), and the $\Psi_{\mathrm{pd}}$ values are shown in Fig. 2.

Simultaneous gas exchange and chlorophyll (Chl) fluorescence measurements: Light-saturated gas exchange and $\mathrm{Chl}$ fluorescence were simultaneously measured on the youngest fully expanded, sun-exposed leaves of five plants per species. Treatments were done from 8:00 h to 11:30 h each day from 15-20 July ('water stress' period) and 23-26 August ('recovery' period), in the same individuals each period, using an open-flow gas-exchange system (LI-6400XT, LI-COR, Inc., Lincoln, NE, USA) equipped with an integrated fluorescence leaf chamber ( $L I-6400-40$, LI-COR, Inc.). In the leaf chamber, a saturated PPFD of $1,200 \mu \mathrm{mol}$ (photon) $\mathrm{m}^{-2} \mathrm{~s}^{-1}$ was provided by a $10: 90$

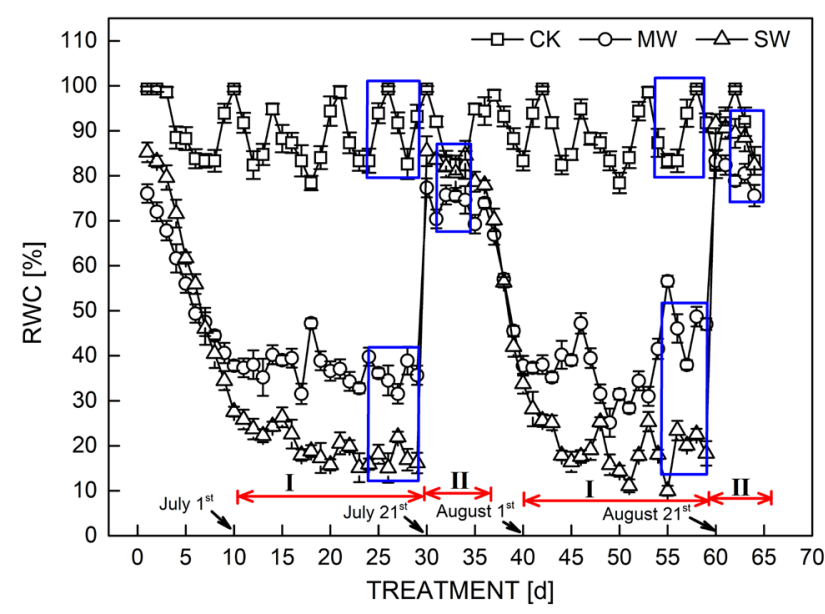

Fig. 1. Variations of daily soil relative water contents (RWC [\%]) during soil drought (I) and rewatering (II) in July and August. All data were the averages of both species' pots with variations $(n=3)$. CK - control; MW - medium water stress; SW - severe water stress. Gas-exchange measurement and leaf sampling were performed in the days marked with blue box (Zhu et al. 2019).

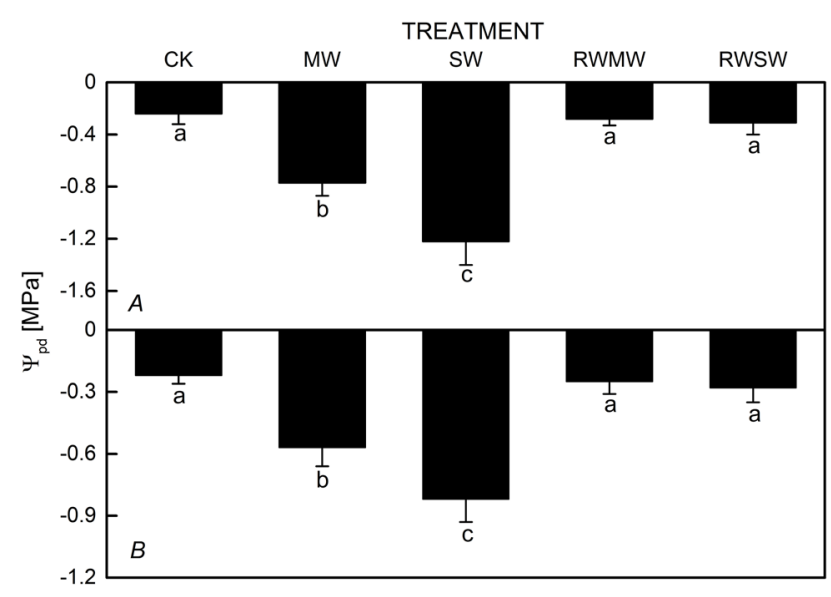

Fig. 2. Predawn leaf water potential $\left(\Psi_{\mathrm{pd}}[\mathrm{MPa}]\right)$ responses to different treatments in Manchurian ash $(A)$ and Mongolian oak $(B)(n=3)$. The error bar represents standard error of all measurements in each individual tree species. Different letters indicate significant difference between each group treatments $(P<0.05)$. CK - control; MW - medium water stress; SW severe water stress; RWMW - rewatering after initial medium water stress; RWSW - rewatering after initial severe water stress (Zhu et al. 2019).

blue:red light source of the LI-6400XT instrument. The leaf temperature was maintained at $25^{\circ} \mathrm{C}$, the relative humidity was approximately $60 \%$, the leaf-to-air vapour pressure deficit (VPD) was between 1.0 and $1.4 \mathrm{kPa}$, and the flow rate was controlled at $300 \mu \mathrm{mol} \mathrm{s}{ }^{-1}$. Gas-exchange parameters, steady-state fluorescence $\left(\mathrm{F}_{\mathrm{s}}\right)$, and maximum fluorescence $\left(\mathrm{F}_{\mathrm{m}}{ }^{\prime}\right)$ with a light-saturating pulse of 7,800 $\mu \mathrm{mol}($ photon $) \mathrm{m}^{-2} \mathrm{~s}^{-1}$ were recorded after reaching a steady state in leaves fully light-adapted for 25-30 min (Loriaux et al. 2013). The actual photochemical efficiency of PSII 
( $\left.\Phi_{\text {PSII }}\right)$ was calculated according to Genty et al. (1989) as follows:

$$
\Phi_{\text {PSII }}=\left(F_{m}{ }^{\prime}-F_{\mathrm{s}}\right) / F_{m}{ }^{\prime}
$$

The electron transport rate (ETR) was then calculated as:

$\mathrm{ETR}=\Phi_{\mathrm{PSII}} \times \mathrm{PPFD} \times \alpha \beta$

where $\alpha$ is the total leaf absorbance and $\beta$ is the partitioning of absorbed quanta between PSI and PSII. In this study, $\alpha \beta$ was calibrated equally as the slope of the relationship between $\Phi_{\mathrm{PSII}}$ and $4 \Phi_{\mathrm{CO} 2}$ (the quantum efficiency of $\mathrm{CO}_{2}$ fixation) obtained from the light-response curves $\left(P_{\mathrm{N}} / \mathrm{PPFD}\right.$ curves), which were measured under low $\mathrm{O}_{2}$ concentration $\left(<1 \%\right.$ ) conditions by injecting pure $\mathrm{N}_{2}$ (Valentini et al. 1995, Xiong et al. 2015a).

Estimation of $\boldsymbol{g}_{\mathrm{m}}$ with the variable $\mathbf{J}$ method: The $g_{\mathrm{m}}$ was estimated with the 'variable $J$ method' described in Harley et al. (1992):

$$
g_{\mathrm{m}}=\frac{P_{\mathrm{N}}}{C_{\mathrm{i}}-\frac{\Gamma^{*}\left[\mathrm{ETR}+8\left(P_{\mathrm{N}}+R_{\mathrm{D}}\right)\right]}{\mathrm{ETR}-4\left(P_{\mathrm{N}}+R_{\mathrm{D}}\right)}}
$$

Here, $P_{\mathrm{N}}$ is the net photosynthetic rate $\left[\mu \mathrm{mol}\left(\mathrm{CO}_{2}\right) \mathrm{m}^{-2} \mathrm{~s}^{-1}\right]$; $C_{\mathrm{i}}$ is the intercellular $\mathrm{CO}_{2}$ concentration $\left[\mu \mathrm{mol}\left(\mathrm{CO}_{2}\right)\right.$ $\mathrm{mol}^{-1}$, which was directly obtained from gas-exchange measurements; $\Gamma^{*}$ represents the $\mathrm{CO}_{2}$-compensation point in the absence of respiration $\left[\mu \mathrm{mol} \mathrm{mol}{ }^{-1}\right.$; and $R_{\mathrm{d}}$ represents mitochondrial respiration in the light $\left[\mu \mathrm{mol} \mathrm{m} \mathrm{m}^{-2} \mathrm{~s}^{-1}\right]$.

$\Gamma^{*}$ and $R_{\mathrm{d}}$ were measured using the Laisk method (Laisk 1977). In this study, three $P_{\mathrm{N}}-C_{\mathrm{i}}$ curves measured under low light $\left[150,100\right.$, and $50 \mu \mathrm{mol}$ (photon) $\left.\mathrm{m}^{-2} \mathrm{~s}^{-1}\right]$ and low $\mathrm{CO}_{2}$ concentrations [from 150 to $40 \mu \mathrm{mol}\left(\mathrm{CO}_{2}\right)$ $\mathrm{mol}^{-1}$ ] formed a triangle range (Sun et al. 2015), and the barycentre of the triangle at the $x$-axis and $y$-axis were considered $\Gamma^{*}$ and $R_{\mathrm{d}}$, respectively. The $\Gamma^{*}$ and $R_{\mathrm{d}}$ values are provided by Zhu et al. (2019).

Photosynthesis limitations analysis: According to Grassi and Magnani (2005) and Wang et al. (2018), the relative changes in light-saturated assimilation were sequentially expressed in terms of parallel relative changes in stomatal to $g_{\mathrm{sc}}$ and $g_{\mathrm{m}}$ and in biochemical capacity (i.e., in maximum carboxylation rate, $V_{\text {cmax }}$ ):

$$
\frac{\mathrm{d} P_{\mathrm{N}}}{P_{\mathrm{N}}}=S C_{\mathrm{L}}+M C_{\mathrm{L}}+B_{\mathrm{L}}=l_{\mathrm{sc}} \times \frac{\mathrm{d} g_{\mathrm{sc}}}{g_{\mathrm{sc}}}+l_{\mathrm{m}} \times \frac{\mathrm{d} g_{\mathrm{m}}}{g_{\mathrm{m}}}+l_{\mathrm{b}} \times \frac{\mathrm{d} V_{\mathrm{cmax}}}{V_{\mathrm{cmax}}}
$$

$$
l_{\mathrm{sc}}=\frac{\frac{g_{\mathrm{tot}}}{g_{\mathrm{sc}}} \times \frac{\partial P_{\mathrm{N}}}{\partial C_{\mathrm{c}}}}{g_{\mathrm{tot}}+\frac{\partial P_{\mathrm{N}}}{\partial C_{\mathrm{c}}}}
$$

$$
l_{\mathrm{m}}=\frac{\frac{g_{\mathrm{tot}}}{g_{\mathrm{m}}} \times \frac{\partial P_{\mathrm{N}}}{\partial C_{\mathrm{c}}}}{g_{\mathrm{tot}}+\frac{\partial P_{\mathrm{N}}}{\partial C_{\mathrm{c}}}}
$$

$$
l_{\mathrm{b}}=\frac{g_{\mathrm{tot}}}{g_{\mathrm{tot}}+\frac{\partial P_{\mathrm{N}}}{\partial C_{\mathrm{c}}}}
$$

Here, $l_{\mathrm{sc}}, l_{\mathrm{m}}$, and $l_{\mathrm{b}}$ are the relative limitations imposed by $g_{\mathrm{sc}}, g_{\mathrm{m}}$, and biochemical capacity, respectively $\left(0<l_{\mathrm{i}}<1\right.$, $\mathrm{i}=\mathrm{sc}, \mathrm{m}, \mathrm{b}) ; g_{\text {tot }}$ is total conductance to $\mathrm{CO}_{2}$ between the leaf surface and carboxylation sites; $S C_{\mathrm{L}}, M C_{\mathrm{L}}$, and $B_{\mathrm{L}}$ are the contributions of $g_{\mathrm{sc}}, g_{\mathrm{m}}$, and biochemical capacity, respectively, to $\mathrm{d} P_{\mathrm{N}} / P_{\mathrm{N}}$; and the sum of contributions due to $g_{\mathrm{sc}}$ and $g_{\mathrm{m}}$ was defined as diffusional limitation $\left(D_{\mathrm{L}}=S C_{\mathrm{L}}+M C_{\mathrm{L}}\right)$, whereas the sum of $g_{\mathrm{m}}$ and biochemical capacity was defined as nonstomatal limitation $\left(N S_{\mathrm{L}}=\right.$ $\left.M C_{\mathrm{L}}+B_{\mathrm{L}}\right)$ (Grassi and Magnani 2005). In the current study, $V_{\text {cmax }}$ was replaced with ETR, which is coupled with $V_{\text {cmax }}$ (Galmés et al. 2007, Galle et al. 2009, Wang et al. 2018, Han et al. 2019), and the fitted photosynthesis parameters at $\Psi_{\mathrm{pd}}=-0.25 \mathrm{MPa}(\mathrm{CK})$ were used as the reference values (Wang et al. 2018). Thus,

$$
\frac{\mathrm{d} x}{x}=\frac{x_{\text {ref }}^{-x}}{x_{\text {ref }}}=\frac{x_{0.25}^{-x}}{x_{0.25}}
$$

where $x$ represents the fitted $g_{\mathrm{sc}}, g_{\mathrm{m}}$ or ETR and $x_{0.25}$ (i.e., $x_{\text {ref }}$ ) represents the $x$ value at $\Psi_{\mathrm{pd}}=-0.25 \mathrm{MPa}(\mathrm{CK})$.

The $g_{\text {tot }}$ was the total conductance to $\mathrm{CO}_{2}$, and it was calculated by Eq. 9:

$$
g_{\text {tot }}=\frac{1}{\frac{1}{g_{\mathrm{sc}}}+\frac{1}{g_{\mathrm{m}}}}
$$

$g_{\mathrm{sc}}=g_{\mathrm{sw}} / 1.6$

where $g_{\text {sw }}$ is the stomatal conductance to water vapour $\left[\mathrm{mol}\left(\mathrm{H}_{2} \mathrm{O}\right) \mathrm{m}^{-2} \mathrm{~s}^{-1}\right]$, and it was directly obtained from gasexchange measurements; 1.6 is the ratio of the diffusivities of $\mathrm{CO}_{2}$ and water in air.

Calculation of leaf $\mathbf{W U E}$ : At the leaf level, the WUE $\mathrm{E}_{\mathrm{i}}$ was defined as the ratio of leaf $P_{\mathrm{N}}$ to $g_{\text {sw }}$ (Osmond et al. 1980), which was calculated as:

$\mathrm{WUE}_{\mathrm{i}}=P_{\mathrm{N}} / g_{\mathrm{sw}}$

Statistical analysis: After testing for normality and homogeneity of variance, using SPSS 17.0 (SPSS, Inc., Chicago, IL, USA), we performed one-way analysis of variance $(A N O V A)$ to detect differences in $l_{\mathrm{sc}}, l_{\mathrm{m}}$, and $l_{\mathrm{b}}$ between the different treatments. Furthermore, regression analyses of $P_{\mathrm{N}}, g_{\mathrm{sc}}$, and $g_{\mathrm{m}}$ and analyses of the correlations between $\mathrm{WUE}_{\mathrm{i}}$ and $l_{\mathrm{sc}}, l_{\mathrm{m}}$, and $l_{\mathrm{b}}$ were performed. The mean values were compared using the least significant difference (LSD) multiple comparison test $(P<0.05$ or $P<0.01)$.

\section{Results}

Responses of relative $l_{\mathrm{sc}}, l_{\mathrm{m}}$, and $l_{\mathrm{b}}$ to soil drought and rewatering: The responses of relative photosynthesis limitations $\left(l_{\mathrm{sc}}, l_{\mathrm{m}}\right.$, and $\left.l_{\mathrm{b}}\right)$ to soil drought and rewatering were shown in Fig. 3. $l_{\mathrm{sc}}, l_{\mathrm{m}}$, and $l_{\mathrm{b}}$ all showed similar changes during soil drought between July and August; specifically, both $l_{\mathrm{sc}}$ and $l_{\mathrm{m}}$ increased with water stress, 
while $l_{\mathrm{b}}$ decreased significantly. Biochemical capacity was found to be the major limiting factor for photosynthesis in well-irrigated saplings in both species, as $l_{\mathrm{b}}$ contributed more than $50 \%$ of the photosynthesis limitations. However, the major limiting factor was the conversion of $l_{\mathrm{m}}$ and $l_{\mathrm{sc}}$ during drought, which increased from 10-20\% to $30-40 \%$ after water stress was established, whereas $l_{\mathrm{b}}$ decreased by $30-50 \%$. In addition, $l_{\mathrm{m}}$ was larger than $l_{\mathrm{sc}}$ in the different treatments in Manchurian ash but lower than $l_{\mathrm{sc}}$ in Mongolian oak overall. Thus, the reductions in plant photosynthesis during soil drought in Manchurian ash might result mainly from the increase in $l_{\mathrm{m}}$, whereas that in Mongolian oak might be largely caused by the increase in $l_{\mathrm{sc}}$.
After rewatering, with the increases in soil RWC and leaf $\Psi_{\mathrm{pd}}$ (data available in Zhu et al. 2019), the photosynthesis limitations changed, with both $l_{\mathrm{m}}$ and $l_{\mathrm{sc}}$ decreasing and $l_{\mathrm{b}}$ increasing. Furthermore, these changes showed some species differences. Average decreases of $7.6 \%(\mathrm{MW})$ and $5.1 \%(\mathrm{SW})$ in $l_{\mathrm{m}}$ relative to the values before rewatering occurred in Manchurian ash, whereas $l_{\mathrm{m}}$ decreased from pre-watering levels by $9.4 \%(\mathrm{MW})$ and $19.6 \%$ (SW) on average in Mongolian oak (Fig. 3). In contrast, $l_{\mathrm{sc}}$ in Manchurian ash increased by approximately $1.0 \%(\mathrm{MW})$ and $3.4 \%(\mathrm{SW})$, whereas that in Mongolian oak increased by $1.6 \%$ in the MW treatment and decreased by $6.4 \%$ in the SW treatment, on average. In contrast to $l_{\mathrm{m}}$ and $l_{\mathrm{sc}}, l_{\mathrm{b}}$ increased after rewatering, by $7.0 \%(\mathrm{MW})$

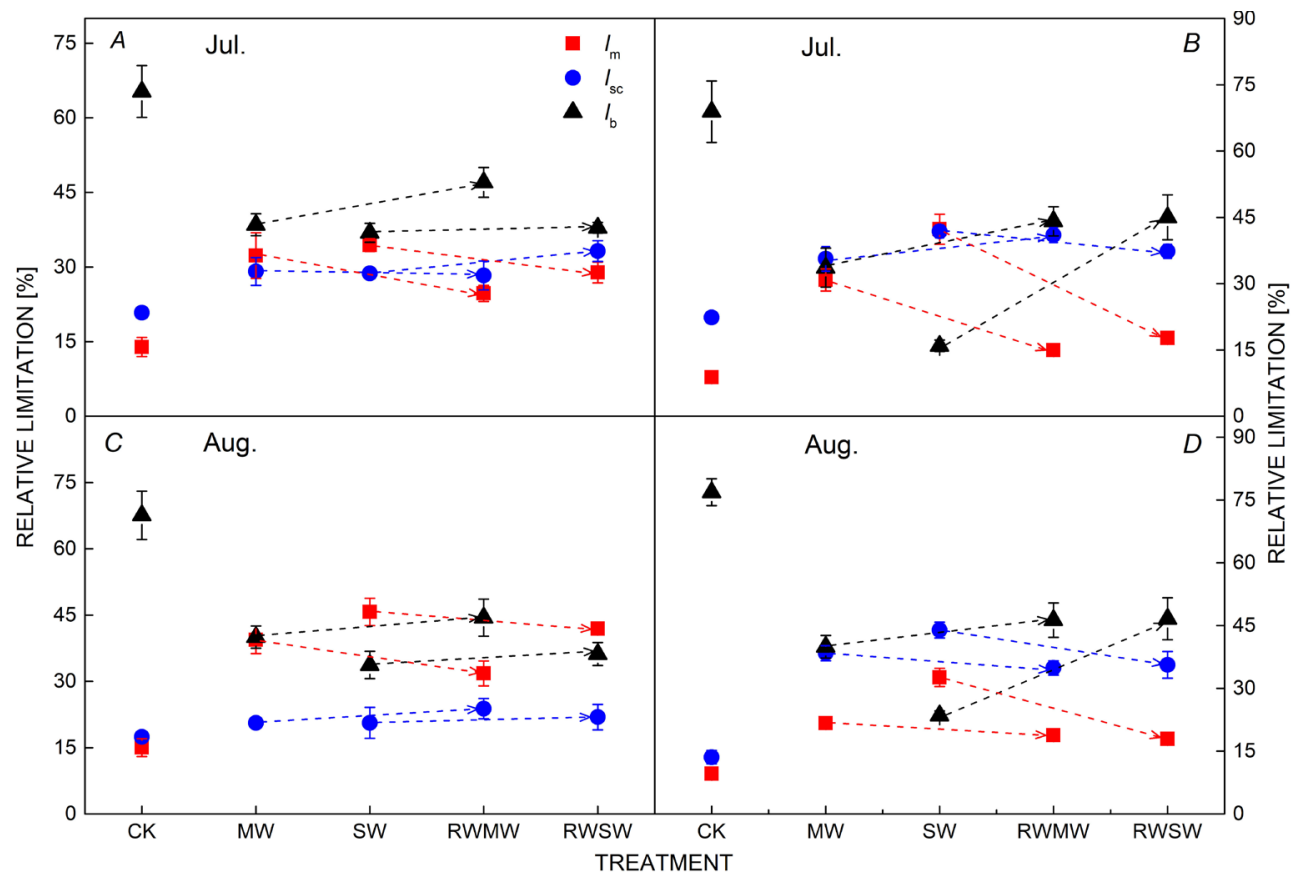

Fig. 3. Effects of soil drought and rewatering on the relative limitations in Manchurian ash $(A, C)$ and Mongolian oak saplings $(B, D)$ in July (Jul.) and August (Aug.). CK control; MW - medium water stress; SW - severe water stress; RWMW rewatering after initial medium water stress; RWSW - rewatering after initial severe water stress. $l_{\mathrm{b}}$ - biochemical limitation; $l_{\mathrm{m}}-$ mesophyll limitation; $l_{\mathrm{sc}}-$ stomatal limitation.

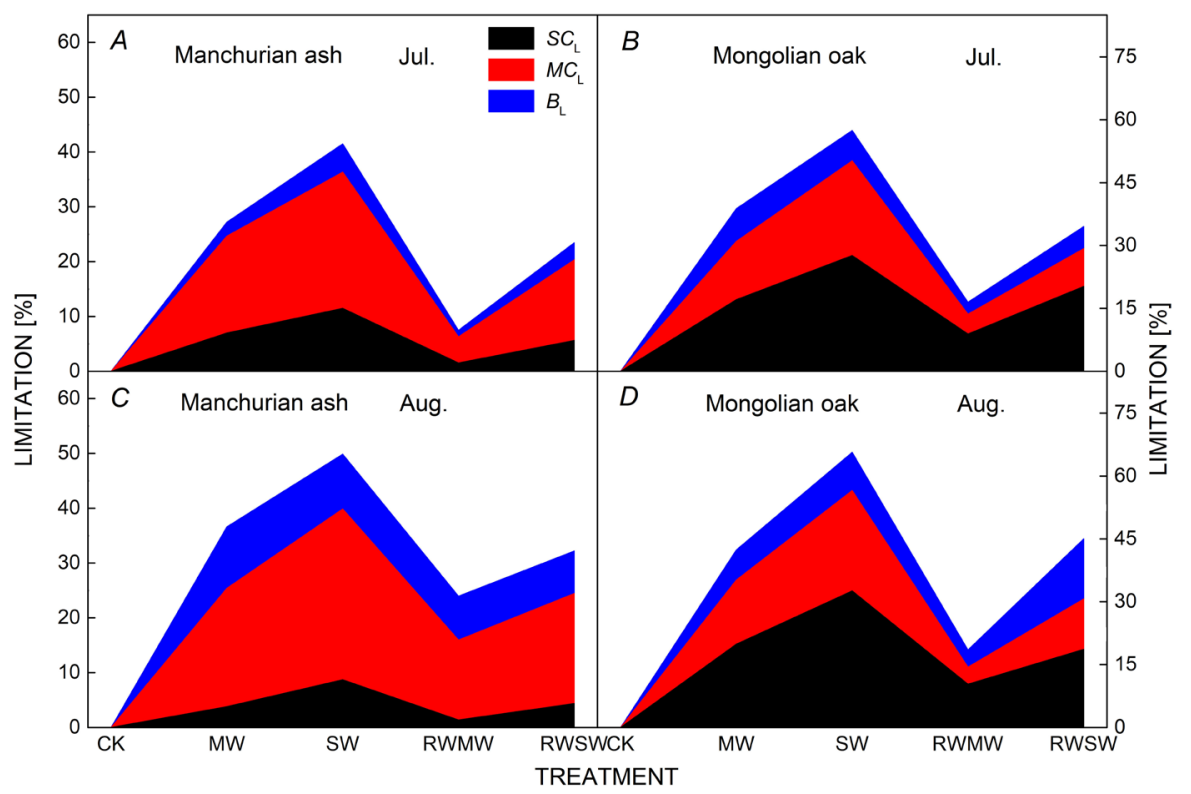

Fig. 4. Contributions of stomatal conductance to $\mathrm{CO}_{2}\left(g_{\mathrm{sc}}\right)\left(S C_{\mathrm{L}}\right)$, mesophyll conductance $\left(g_{\mathrm{m}}\right)\left(M C_{\mathrm{L}}\right)$, and biochemical capacity $\left(B_{\mathrm{L}}\right)$ to photosynthesis change $\left(\mathrm{d} P_{\mathrm{N}} / P_{\mathrm{N}}\right)$ for controlled, water-stressed, and rewatered saplings during soil and rewatering in Manchurian ash and Mongolian oak in July (Jul.) and August (Aug.). CK - control; MW medium water stress; SW - severe water stress; RWMW - rewatering after initial medium water stress; RWSW - rewatering after initial severe water stress. 
and $1.8 \%(\mathrm{SW})$ on average in Manchurian ash and greater extents, $8.5 \%$ (MW) and 26.1\% (SW), in Mongolian oak.

Photosynthesis contributions of $g_{\text {sc }}, g_{\mathrm{m}}$, and biochemical capacity during soil drought and rewatering: Fig. 4 showed the contributions of $g_{\mathrm{sc}}, g_{\mathrm{m}}$, and biochemical capacity $\left(S C_{\mathrm{L}}, M C_{\mathrm{L}}\right.$, and $\left.B_{\mathrm{L}}\right)$ to photosynthesis change $\left(\mathrm{d} P_{\mathrm{N}} / P_{\mathrm{N}}\right)$ in this study. $S C_{\mathrm{L}}, M C_{\mathrm{L}}$, and $B_{\mathrm{L}}$ all increased compared to their corresponding values in the wellirrigated treatment after water stress was established. After rewatering, the values of $S C_{\mathrm{L}}, M C_{\mathrm{L}}$, and $B_{\mathrm{L}}$ decreased in both species, and $M C_{\mathrm{L}}$ was still the largest in Manchurian ash, whereas $S C_{\mathrm{L}}$ was the largest in Mongolian oak. These results indicated that photosynthesis recovery was mostly affected by $l_{\mathrm{m}}$ in Manchurian ash and by $l_{\mathrm{sc}}$ in Mongolian oak. Significant differences between treatments were found for $S C_{\mathrm{L}}, M C_{\mathrm{L}}$, and $B_{\mathrm{L}}$ in both species. Upon rewatering, all three limitations became much more similar to each other than they were under stress. In addition, the contributions of diffusional limitations $\left(S C_{\mathrm{L}}+M C_{\mathrm{L}}\right)$ were much larger than those of biochemical limitation $\left(B_{\mathrm{L}}\right)$ over the two periods of water stress and rewatering, indicating that $\mathrm{CO}_{2}$ diffusion inside leaves had a larger effect on plant photosynthesis than did other biochemical processes.

Changes in leaf $\mathbf{W U E}_{\mathrm{i}}$ : WUE $\mathrm{W}_{\mathrm{i}}$ (Fig. 5) decreased in both species with water stress, but after rewatering, it increased by $13.9 \%$ (RWMW) and $19.8 \%$ (RWSW) in July and by $25.2 \%$ (RWMW) and $22.5 \%$ (RWSW) in August in Manchurian ash and by $4.4 \%$ (RWMW) and 9.2\% (RWSW) in July and by $8.4 \%$ (RWMW) and $11.1 \%$ (RWSW) in August in Mongolian oak. Overall, some differences in WUE $E_{i}$ were observed depending on the extent of stress and rewatering treatment. Mongolian oak maintained a much larger WUE $_{\mathrm{i}}$ than that of Manchurian ash during water stress and rewatering in July and August.
Relationships between leaf $\mathrm{WUE}_{\mathrm{i}}$ and photosynthesis limitations: We explored the relationships between $\mathrm{WUE}_{\mathrm{i}}$ and relative photosynthesis limitations $\left(l_{\mathrm{m}}, l_{\mathrm{sc}}\right.$, and $\left.l_{\mathrm{b}}\right)$ in both species (Fig. 6). The results showed that $l_{\mathrm{m}}$ and $l_{\mathrm{sc}}$ each maintained a negative correlation with $\mathrm{WUE}_{\mathrm{i}}$, whereas $l_{\mathrm{b}}$ maintained a positive correlation with $\mathrm{WUE}_{\mathrm{i}}$. The correlation coefficient $(r)$ values between $\mathrm{WUE}_{\mathrm{i}}$ and $l_{\mathrm{m}}, l_{\mathrm{sc}}$, and $l_{\mathrm{b}}$ were $-0.525,-0.386$, and 0.448 , respectively, in Manchurian ash and $-0.449,-0.395$, and 0.509, respectively, in Mongolian oak.

Relationships between leaf $\boldsymbol{P}_{\mathrm{N}}$ and $\boldsymbol{g}_{\mathrm{m}}, \boldsymbol{g}_{\mathrm{sc}}, \boldsymbol{g}_{\text {tot }}$, and $\boldsymbol{l}_{\mathrm{b}}$ : Leaf $P_{\mathrm{N}}$ in the two varieties both showed a regression relationship with $g_{\mathrm{m}}, g_{\mathrm{sc}}$, and $g_{\text {tot }}$ during the drought and recovery treatments (Fig. 7), and this regression weakened after rewatering, reflected by the declined slope during recovery. But the $P_{\mathrm{N}}$ did not show any regression with the $l_{\mathrm{b}}$ in ash and oak saplings.

Relationships between leaf $\mathrm{WUE}_{\mathrm{i}}$ and $g_{\mathrm{m}}, g_{\mathrm{sc}}$, and $\boldsymbol{g}_{\mathrm{m}} / \boldsymbol{g}_{\mathrm{sc}}$ : Leaf $\mathrm{WUE}_{\mathrm{i}}$ did not correlate with $g_{\mathrm{m}}$ and $g_{\mathrm{sc}}$, but a strong correlation between $\mathrm{WUE}_{\mathrm{i}}$ and $g_{\mathrm{m}} / g_{\mathrm{sc}}$ was observed in these two species (Fig. $8, P<0.05$ ).

\section{Discussion}

Photosynthesis roles of $l_{\mathrm{sc}}, l_{\mathrm{m}}$, and $l_{\mathrm{b}}$ changing with soil drought and rewatering: Our data showed that photosynthesis limitations imposed by changes in $g_{\mathrm{sc}}$ and $g_{\mathrm{m}}$ and biochemical capacity (i.e., $l_{\mathrm{sc}}, l_{\mathrm{m}}$, and $l_{\mathrm{b}}$ ) during soil drought and rewatering vary with soil water fluctuations. Biochemical capacity limitation plays a primary role in well-irrigated saplings, with $l_{\mathrm{b}}$ being the largest among the studied limitations, but this limitation gradually changes as soil water availability decreases. Once water stress is established, both $l_{\mathrm{sc}}$ and $l_{\mathrm{m}}$ markedly increase while $l_{\mathrm{b}}$

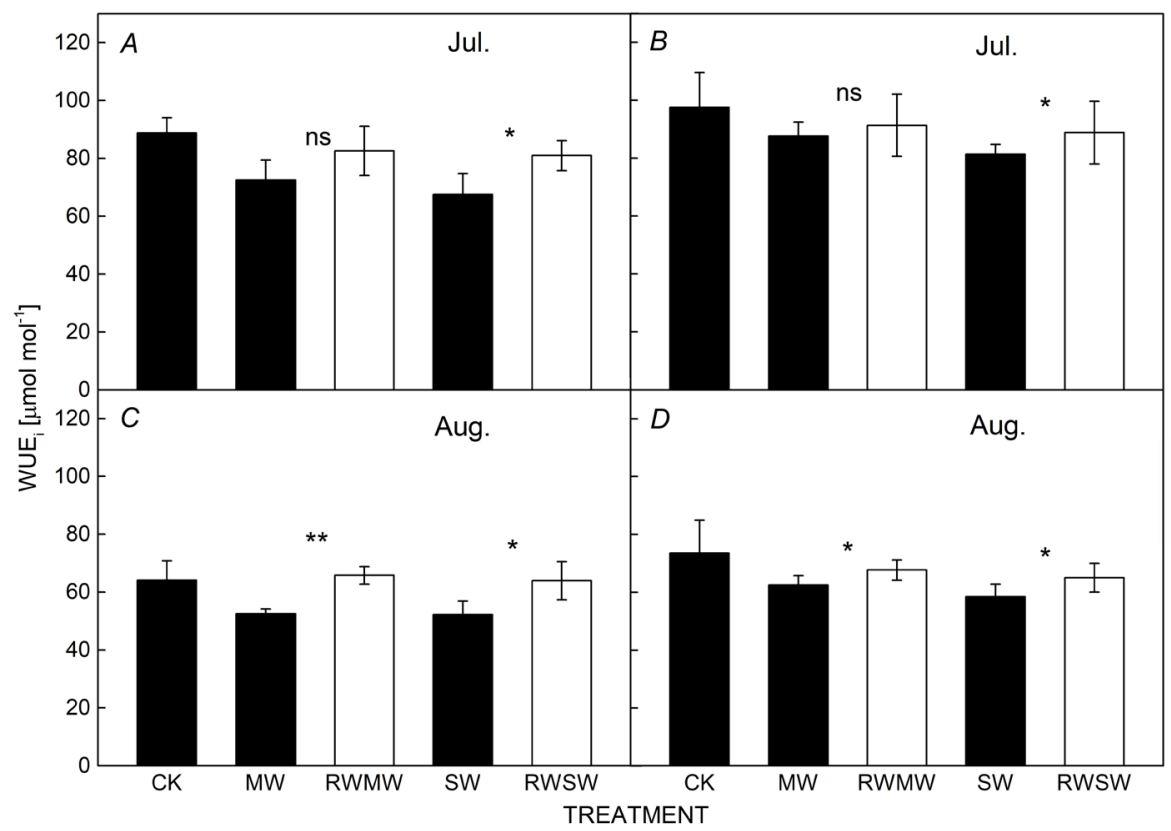

Fig. 5. Changes of leaf intrinsic water-use efficiency $\left(\mathrm{WUE}_{\mathrm{i}}\right)$ during soil drought and rewatering in Manchurian ash $(A, C)$ and Mongolian oak saplings $(B, D)$ in July (Jul.) and August (Aug.). Values were mean \pm SE $(n=5)$. The associated probabilities were shown (ns, not significant; * $P<0.05$; ** $P<0.01)$. $\mathrm{CK}$ - control; MW - medium water stress; SW - severe water stress; RWMW - rewatering after initial medium water stress; RWSW rewatering after initial severe water stress. 


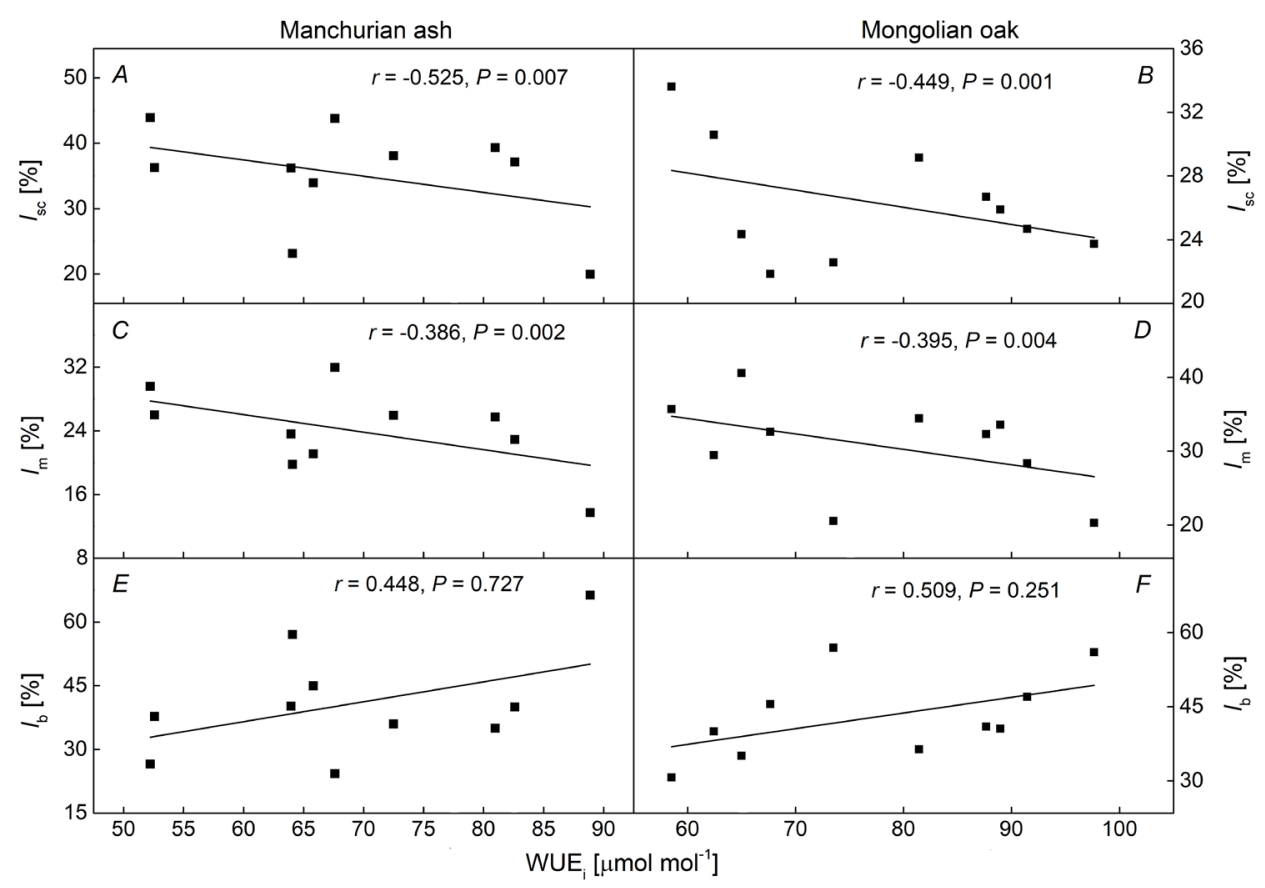

Fig. 6. Relationships between leaf intrinsic water-use efficiency $\left(\mathrm{WUE}_{\mathrm{i}}\right)$ and mesophyll limitation $\left(l_{\mathrm{m}}\right)$, stomatal limitation $\left(l_{\mathrm{sc}}\right)$, and biochemical limitation $\left(l_{\mathrm{b}}\right)$ in Manchurian ash $(A, C, E)$ and Mongolian oak saplings $(B, D, F)$.
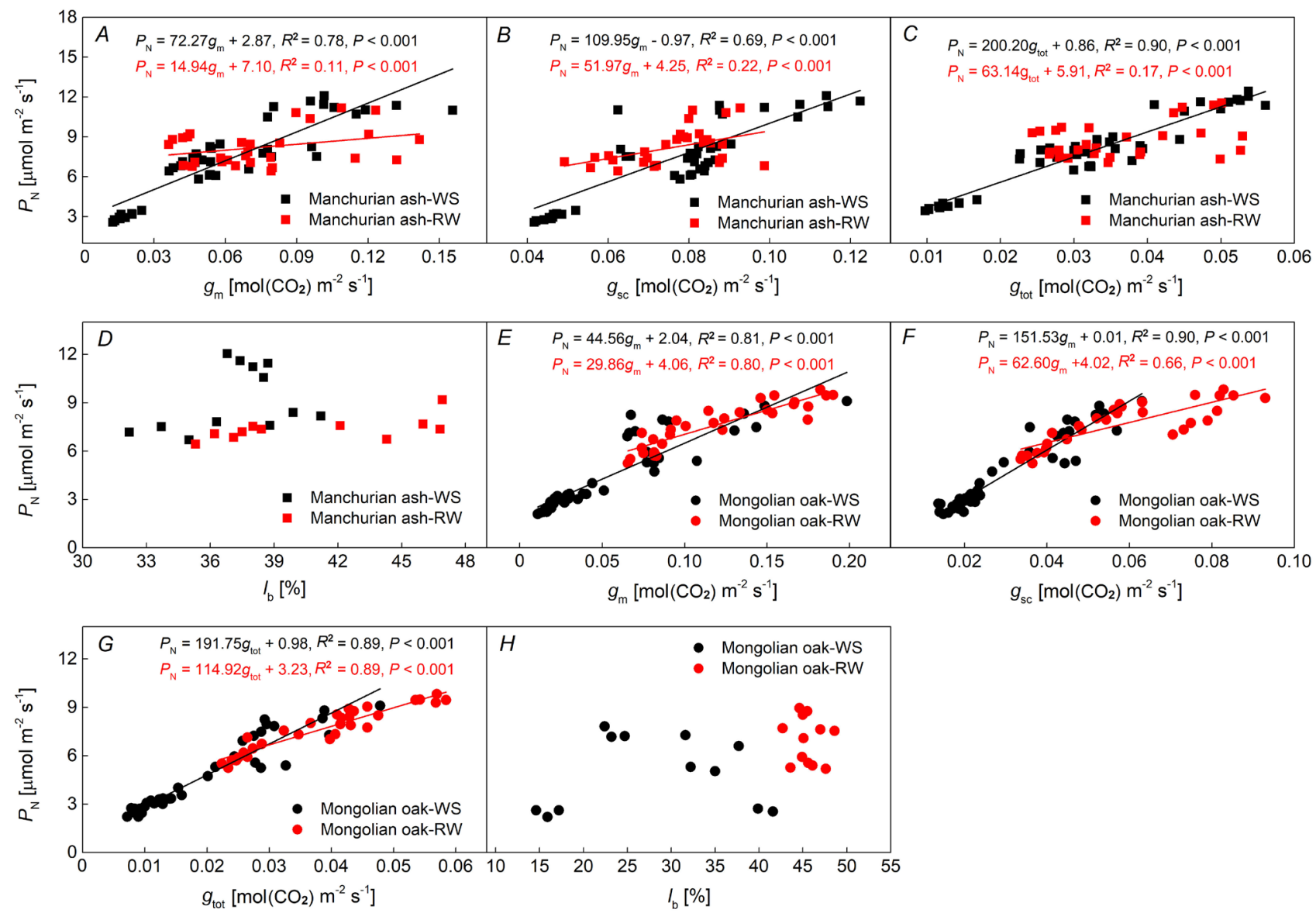

Fig. 7. Regression relationships between net photosynthetic rate $\left(P_{\mathrm{N}}\right)$ and mesophyll conductance $\left(g_{\mathrm{m}}\right)(A, E)$, stomatal conductance to $\mathrm{CO}_{2}\left(g_{\mathrm{sc}}\right)(B, F)$, total conductance to $\mathrm{CO}_{2}\left(g_{\text {tot }}\right)(C, G)$, and biochemical limitation $\left(l_{\mathrm{b}}\right)(D, H)$ in Manchurian ash and Mongolian oak saplings during soil drought and rewatering. WS - water stress treatment; RW - rewatering treatment. 

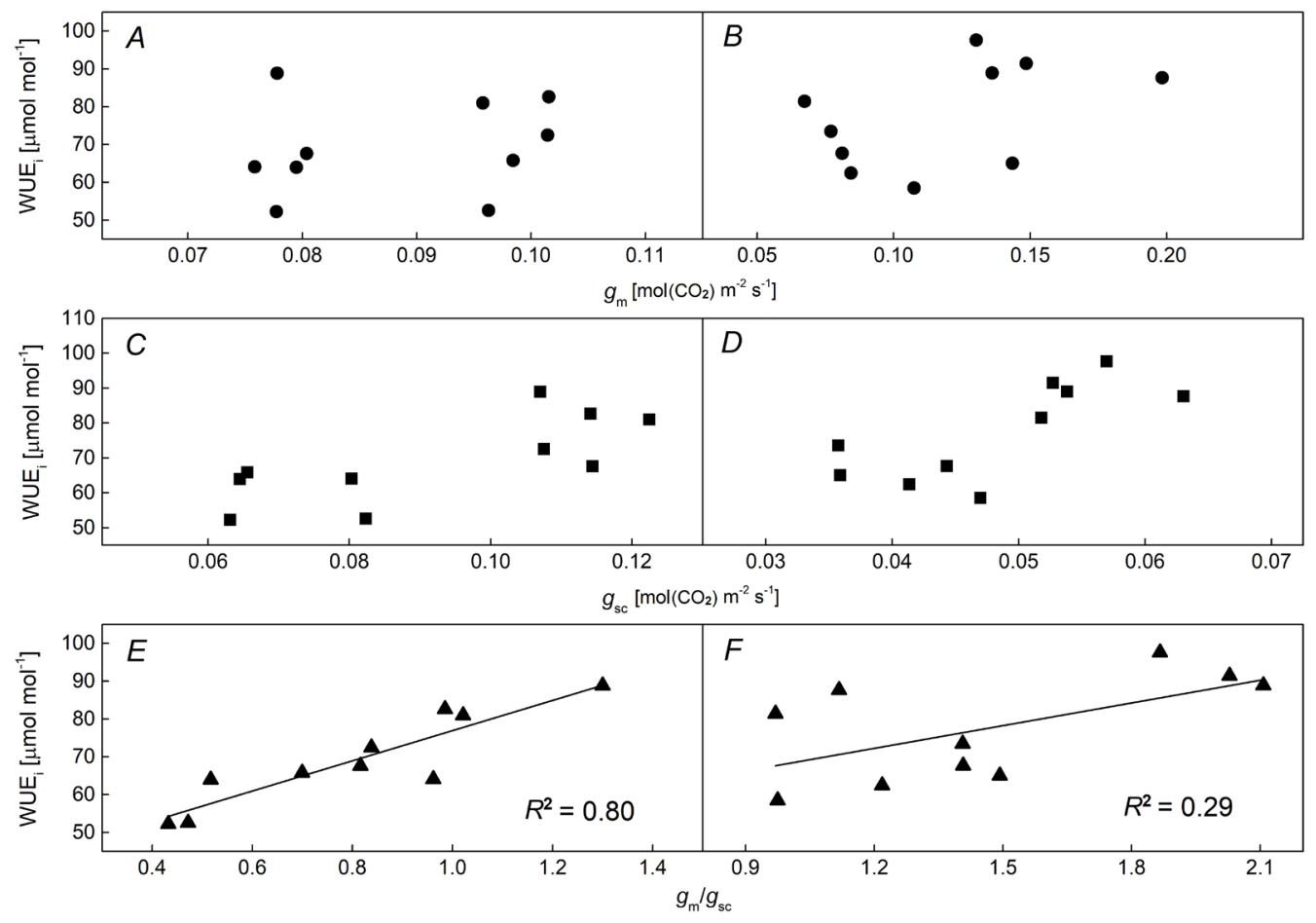

Fig. 8. Relationships between leaf intrinsic water-use efficiency (WUE $)$ and mesophyll conductance $\left(g_{\mathrm{m}}\right)$, stomatal conductance to $\mathrm{CO}_{2}$ $\left(g_{\mathrm{sc}}\right)$, and $g_{\mathrm{m}} / g_{\mathrm{sc}}$ in Manchurian ash $(A, C, E)$ and Mongolian oak saplings $(B, D, F)(P<0.05)$.

decreases, indicating that $\mathrm{CO}_{2}$ diffusional conductances decline while plant metabolic activities strengthened. The primary limitation factor is converted to $l_{\mathrm{m}}$ in Manchurian ash and $l_{\text {sc }}$ in Mongolian oak during soil drought. Thus, diffusive (stomatal and mesophyll) limitations are the main limiting factors for photosynthesis in ash and oak; this finding is partially consistent with the study of PegueroPina et al. (2018b). The declines in $g_{\mathrm{sc}}$ and $g_{\mathrm{m}}$ have larger negative effects than the changes in metabolic activity on photosynthesis and ultimately lead to a decrease in $P_{\mathrm{N}}$. Furthermore, with water stress aggravation, $l_{\mathrm{b}}$ continues to decrease, causing $B_{\mathrm{L}}$ to become less than $10 \%$ (Fig. 4 ), i.e., nearly negligible, and the total contributions of diffusional limitations $\left(D_{\mathrm{L}}=S C_{\mathrm{L}}+M C_{\mathrm{L}}\right)$ gradually account for all photosynthesis limitations. Diffusional processes appear to have a prominent role in photosynthesis during soil drought, an observation that is strongly supported by the studies of Grassi and Magnani (2005) and Galmés et al. (2007), who identified the primary role of diffusional limitations $\left(l_{\mathrm{sc}}+l_{\mathrm{m}}\right)$ in photosynthesis. This prominent role of diffusional processes may be mainly due to the common stomatal closure in pot experiments under water stress conditions, wherein plants experience more rapid dehydration than those under field conditions (Gunasekera and Berkowitz 1992, Kubiskem and Abrams 1993).

In the present study, $l_{\mathrm{m}}$ is larger than $l_{\mathrm{sc}}$ in Manchurian ash, whereas $l_{\mathrm{sc}}$ is much larger than $l_{\mathrm{m}}$ in Mongolian oak (Fig. 3), indicating that during soil drought, Mongolian oak maintains a lower $g_{\text {sc }}$ than $g_{\mathrm{m}}$ while Manchurian ash maintains a larger $g_{\mathrm{sc}}$ than $g_{\mathrm{m}}$. Drought-tolerant species, such as Mongolian oak, close their stomata earlier than drought-intolerant species to avoid leaf dehydration and the generation of excessive tension in the water column inside the xylem under drought (Aranda et al. 2012b). However, for less drought-tolerant species, such as Manchurian ash, the tendency to resist soil drought may be to minimize photosynthesis evapotranspiration. In a previous study, ash did not close its stomata to the same extent as oak under water stress, although the $g_{\text {sw }}$ of wellwatered plants was higher in ash than that in oak (Zhu et al. 2019). The stomatal control of water loss is more effective in oak than that in ash. The lack of effective stomatal regulation of water loss leads to lower leaf water potential in ash than in oak, which induces damage to the mesophyll cells in ash (as observed from photographs of mesophyll cells and aquaporin (AQP) activity data in Zhu et al. 2019) and reduces $g_{\mathrm{m}}$ more in ash than that in oak. Water and $\mathrm{CO}_{2}$ diffusion in leaves share common pathways (Xiong et al. 2015b), and $\mathrm{CO}_{2}$ diffusion in Manchurian ash may be seriously weakened simultaneously with water diffusion under water stress, as ash was more susceptible than oak to soil water availability (Grassi and Magnani 2005).

Soil rewatering triggers a great recovery in photosynthesis in this study, and we believe the declines in $l_{\mathrm{sc}}$ and $l_{\mathrm{m}}$ caused by the improvements in $\mathrm{CO}_{2}$ diffusion are the main reasons for this recovery. Furthermore, plants are able to repair embolized xylem conduits by pushing water from living conduit-associated parenchyma cells into gasfilled lumina when the bulk of water-transporting xylem is still under tension (Bucci et al. 2003, Hacke and Sperry 2003). The great photosynthesis recovery in the two species may be also mediated by the development of new 
xylem or by restoring the function of previously embolized vessels (Resco et al. 2009, Brodribb et al. 2010). Soil rewatering does not change the photosynthesis roles of $l_{\mathrm{sc}}$, $l_{\mathrm{m}}$, and $l_{\mathrm{b}}$, and it strengthens the diffusional contributions to photosynthesis recovery, as evidenced by the significantly larger $D_{\mathrm{L}}$ than $N S_{\mathrm{L}}$ during recovery and by the absence of a significant regression relationship of $l_{\mathrm{b}}$ with $P_{\mathrm{N}}$ before and after soil rewatering in the two varieties (Fig. $7 D, H)$. When $D_{\mathrm{L}}$ is further partitioned into its components, we found that over the whole experiment, $M C_{\mathrm{L}}$ played the largest role in Manchurian ash, whereas $S C_{\mathrm{L}}$ played the largest role in Mongolian oak. Nevertheless, soil rewatering significantly weakens the primary roles of $l_{\mathrm{m}}$ and $l_{\mathrm{sc}}$ : the slopes of the regression relationships between $P_{\mathrm{N}}$ and $g_{\mathrm{m}}, g_{\mathrm{s}}$, and $g_{\text {tot }}$ are weaker in both species (Fig. 7) during recovery than during soil drought.

Overall, the contributions of $g_{\mathrm{sc}}\left(S C_{\mathrm{L}}\right)$ and $g_{\mathrm{m}}\left(M C_{\mathrm{L}}\right)$ and biochemical capacity $\left(B_{\mathrm{L}}\right)$ to photosynthesis change $\left(\mathrm{d} P_{\mathrm{N}} / P_{\mathrm{N}}\right)$ during drought and recovery were larger in August, i.e., upon the second drought, than that in July, indicating that the effects of $g_{\mathrm{sc}}$ and $g_{\mathrm{m}}$ and biochemical capacity on photosynthesis were strengthened with plant growth. The above changes in $S C_{\mathrm{L}}, M C_{\mathrm{L}}$, and $B_{\mathrm{L}}$ from July to August should occur largely due to the changes in AQP and carbonic anhydrase (CA) activities, as the activities of these proteins both decreased during drought and recover after rewatering (Zhu et al. 2019), although we did not measure their activities from July to August. In addition, Manchurian ash and Mongolian oak have a less than four month growing cycle (from June to early September) in the Changbai Mountain areas, and their metabolic parameters, such as $P_{\mathrm{N}}$, begun to weaken in August (Zhu et al. 2019). Consequently, the contributions of $g_{\mathrm{sc}}$ and $g_{\mathrm{m}}$ and biochemical capacity to $\mathrm{d} P_{\mathrm{N}} / P_{\mathrm{N}}$ can be expected to be enlarged in August.

Our results agree with those of Galmés et al. (2007) and Cai et al. (2015), who confirmed the primary role of $l_{\mathrm{m}}$ in photosynthesis recovery for species in the Balearic Islands and Rhododendron delavayi Franch. In addition, the studies of Flexas et al. (2009) and Perez-Martin et al. (2014) emphasized the dominant role of $l_{\mathrm{sc}}$ in Vitis berlandieri $\times$ Vitis rupestris and $O$. europaea L. var. Manzanilla, consistent with our results. However, in the present study, the role of $B_{\mathrm{L}}$ was nearly negligible; in contrast, Ennahli and Earl (2005) suggested that photosynthesis recovery in Gossypium hirsutum L. was mostly affected by $l_{\text {b }}$, whereas influences of $l_{\mathrm{sc}}$ and $l_{\mathrm{m}}$ were almost absent. Another difference between the present results and previous results is that in the present study, the primary roles of $l_{\mathrm{m}}$ and $l_{\mathrm{sc}}$ were constant over periods of soil drought and rewatering, whereas in other studies, they varied with drought intensity and rewatering treatment (Grassi and Magnani 2005, Galmés et al. 2007). Genotypic variation may be an important reason for this difference, as Mongolian oak maintains a better water status and higher $\mathrm{WUE}_{\mathrm{i}}$ than ash; the reasons need to be explored. Furthermore, the small bias resulting from the calculation of $l_{\mathrm{b}}$ using ETR (Wang et al. 2018) rather than $V_{\text {cmax }}$ (Flexas et al. 2009, Cano et al. 2014) may influence the measurements of changes in $l_{\mathrm{sc}}$ and $l_{\mathrm{m}}$ during water stress and rewatering. Given that
$V_{\text {cmax }}$ (or ETR here) is directly proportional to $\mathrm{d} P_{\mathrm{N}} / \mathrm{d} C_{\mathrm{c}}$, the use of ETR instead of $V_{\text {cmax }}$ may have artificially increased $l_{\mathrm{b}}$ and decreased $l_{\mathrm{sc}}$ and $l_{\mathrm{m}}$. Nevertheless, this potential bias should not affect the relative strengths of $l_{\mathrm{sc}}$ and $l_{\mathrm{m}}$.

Species dependence on the photosynthesis roles of $l_{\mathrm{sc}}, l_{\mathrm{m}}$ and $\boldsymbol{l}_{\mathrm{b}}$ and leaf $\mathbf{W U E} \mathbf{E}_{\mathrm{i}}$ : The above discussion of previous studies suggests that the primary factors among $l_{\mathrm{sc}}, l_{\mathrm{m}}$, and $l_{\mathrm{b}}$ may be species dependent, which is consistent with our results that Manchurian ash has $l_{\mathrm{m}}$ as the primary factor influencing photosynthesis in water-limited conditions, whereas in Mongolian oak, $l_{\mathrm{sc}}$ maintains a primary role. Different species, provenances and cultivars differ in their ability to adapt $g_{\text {sc }}$ or leaf biochemical capacity for carbon fixation to optimize carbon gain with respect to water loss (Hommel et al. 2014). Such differences in optimization strategies could strongly affect synecological interactions, especially at sites exposed to periodic drought (Grams et al. 2007, Niinemets et al. 2009). As a less droughttolerant species (Epron and Dreyer 1993, Grassi and Magnani 2005), Manchurian ash does not close many stomata despite reaching lower predawn water potential than Mongolian oak. This pattern may be due to the higher sensitivity of $g_{\mathrm{m}}$ to changes in SWC than $g_{\mathrm{sc}}$ in ash, as $g_{\mathrm{m}}$ decreases much more than $g_{\text {sc }}$ under water stress conditions (Zhu et al. 2019). Soil rewatering may not change the primary role of diffusional limitations, but it still influences the roles of $g_{\mathrm{m}}, g_{\mathrm{sc}}$ and biochemistry in limiting $P_{\mathrm{N}}$. After rewatering, the $l_{\mathrm{sc}}$ of the two varieties is significantly reduced under the initial SW treatment, whereas a significant reduction in $l_{\mathrm{m}}$ occurs under the two drought treatments.

Barbour and Kaiser (2016) suggested that the combination of high $l_{\mathrm{sc}}$ and low $l_{\mathrm{m}}$ should produce high leaf water-use efficiency, reflecting the close correlations between water-use efficiency and $l_{\mathrm{sc}}$ and $l_{\mathrm{m}}$. In the present study, $l_{\mathrm{sc}}$ and $l_{\mathrm{m}}$ each shows a negative correlation with $\mathrm{WUE}_{\mathrm{i}}$ (Fig. 6), and a strong correlation is observed between $\mathrm{WUE}_{\mathrm{i}}$ and $g_{\mathrm{m}} / g_{\mathrm{sc}}$ (Fig. $8 E, F$ ) but not $g_{\mathrm{m}}$ or $g_{\mathrm{sc}}$ (Fig. $8 A-D$ ). These results suggest that $\mathrm{WUE}_{\mathrm{i}}$ correlates with neither $g_{\mathrm{m}}$ nor $g_{\mathrm{sc}}$ but is strongly affected by the ratio of $g_{\mathrm{m}} / g_{\mathrm{sc}}$ (Flexas et al. 2013, Han et al. 2016), possibly because stomata control $\mathrm{CO}_{2}$ gain and water loss, whereas $g_{\mathrm{m}}$ is related only to $\mathrm{CO}_{2}$ diffusion inside leaves. The $l_{\mathrm{b}}$ in this study shows a positive correlation with $\mathrm{WUE}_{\mathrm{i}}$ (Fig. 6), further demonstrating the regulation via biochemical mechanisms of the variability of $\mathrm{WUE}_{\mathrm{i}}$ under moderate and severe drought conditions. Hence, the differences in water-use efficiency are explained by changes in the balance between photosynthesis limitations.

Our results show a generally higher $\mathrm{WUE}_{\mathrm{i}}$ in Mongolian oak than that in Manchurian ash, which is related to the larger $S_{\mathrm{L}}$ and lower $M C_{\mathrm{L}}$ in the former species. Since the investment of large amounts of reserves in the development of a large and deep root system might be crucial for trees in water-limited habitats (Bloom et al. 1985), the difference in $\mathrm{WUE}_{\mathrm{i}}$ between the two varieties may be largely due to their differences in physiological mechanisms. Mongolian oak has a more developed root system and much larger leaf hydraulic conductance $\left(K_{\text {leaf }}\right)$ and stem vessel diameter 
( $\left.D_{\text {stem }}\right)$ than Manchurian ash (Zhang et al. 2020); because $K_{\text {leaf }}$ is highly coordinated with both $g_{\text {sc }}$ and $P_{\mathrm{N}}$, Mongolian oak can thus absorb and use much more water from deeper parts of the soil than Manchurian ash (Aasamaa et al. 2001, Brodribb and Holbrook 2006). Such ability would be of major importance under water stress conditions (Shatil-Cohen et al. 2011). Hence, a species' dependence on the photosynthesis roles of $l_{\mathrm{sc}}$ and $l_{\mathrm{m}}$ should be strongly related to plant water status and water-use capacity; this expectation is indirectly supported by the finding of Tomás et al. (2014) that $g_{\mathrm{sc}}$ and $g_{\mathrm{m}}$ greatly affected leaf water-use efficiency.

In addition, we obtained the unexpected result that the $\mathrm{WUE}_{\mathrm{i}}$ under the initial MW and SW conditions was lower than that under the CK condition in both species (Fig. 5). This result may be largely due to the failure to consider the cuticular transpiration $\left(g_{\mathrm{cw}}\right)$ in this study, which is used to correct $C_{\mathrm{i}}$ and recalculate $g_{\mathrm{sw}}$ (Warren et al. 2011, Cano et al. 2014) and hence affects $\mathrm{WUE}_{\mathrm{i}}$. The failure to consider $g_{\mathrm{cw}}$ could give rise to an apparent biphasic response of $C_{\mathrm{i}}$ (or $\mathrm{WUE}_{\mathrm{i}}$ ) to water stress, whereby $C_{\mathrm{i}}$ initially decreased under moderate stress but then increased under severe stress (Medrano et al. 2002). Furthermore, in this study, there was no separation of the treatment and ontogenetic effects on multiple estimations to well-watered plants, which may result in an unclear meaning of CK.

Conclusion: The $l_{\mathrm{sc}}$ and $l_{\mathrm{m}}$ increased while $l_{\mathrm{b}}$ decreased with water stress during soil drought in both Manchurian ash and Mongolian oak. Soil rewatering decreased both $l_{\mathrm{sc}}$ and $l_{\mathrm{m}}$ but increased $l_{\mathrm{b}}$. The primary limiting factor for photosynthesis in well-irrigated saplings is biochemical capacity (i.e., $l_{\mathrm{b}}$ ), but when water stress was established, the primary limiting factor was gradually converted to increased mesophyll resistance (i.e., $l_{\mathrm{m}}$ ) in Manchurian ash and stomatal closure (i.e., $l_{\mathrm{sc}}$ ) in Mongolian oak. Soil rewatering did not change the primary roles of $l_{\mathrm{sc}}$ and $l_{\mathrm{m}}$ and made the largest $g_{\mathrm{m}}$ contribution $\left(M C_{\mathrm{L}}\right)$ to photosynthesis recovery in Manchurian ash and the largest $g_{\text {sc }}$ contribution $\left(S C_{\mathrm{L}}\right)$ to that in Mongolian oak. Mongolian oak maintained higher $W_{U E}$ than Manchurian ash during soil drought and rewatering. Therefore, leaf $\mathrm{WUE}_{\mathrm{i}}$ can be directly influenced by photosynthesis limitations, becoming larger as biochemical limitations increase at the expense of diffusional limitations $\left(l_{\mathrm{sc}}\right.$ and $\left.l_{\mathrm{m}}\right)$.

\section{References}

Aasamaa K., Sober A., Rahi M.: Leaf anatomical characteristics associated with shoot hydraulic conductance, stomatal conductance and stomatal sensitivity to changes of leaf water status in temperate deciduous trees. - Funct. Plant Biol. 28: 765-774, 2001

Aranda I., Gil-Pelegrín E., Gascó A. et al.: Drought response in forest trees: From the species to the gene. - In: Aroca R. (ed.): Plant Responses to Drought Stress. Pp. 293-333. Springer, Berlin-Heidelberg 2012b.

Aranda I., Rodriguez-Calcerrada J., Robson T.M. et al.: Stomatal and non-stomatal limitations on leaf carbon assimilation in beech (Fagus sylvatica L.) seedlings under natural conditions. - Forest Syst. 21: 405-417, 2012a.
Barbour M.M., Kaiser B.N.: The response of mesophyll conductance to nitrogen and water availability differs between wheat genotypes. - Plant Sci. 251: 119-127, 2016.

Bloom A.J., Chapin III F.S., Mooney H.A.: Resource limitation in plants: An economic analogy. - Annu. Rev. Ecol. Syst. 16: 363-392, 1985.

Brodribb T.J., Bowman D.J.M.S., Nichols S. et al.: Xylem function and growth rate interact to determine recovery rates after exposure to extreme water deficit. - New Phytol. 188: 533-542, 2010.

Brodribb T.J., Holbrook N.M.: Declining hydraulic efficiency as transpiring leaves desiccate: two types of response. - Plant Cell Environ. 29: 2205-2215, 2006.

Bucci S.J., Scholz F.G., Goldstein G. et al.: Dynamic changes in hydraulic conductivity in petioles of two savanna tree species: factors and mechanisms contributing to the refilling of embolized vessels. - Plant Cell Environ. 26: 1633-1645, 2003.

Cai Y.F., Wang J.H., Li S.F. et al.: Photosynthetic response of an alpine plant, Rhododendron delavayi Franch, to water stress and rewatering: The role of mesophyll conductance. - Front. Plant Sci. 6: 1089, 2015.

Cai Y.F., Zhang S.B., Hu H., Li S.Y.: Photosynthetic performance and acclimation of Incarvillea delavayi to water stress. - Biol. Plantarum 54: 89-96, 2010.

Cano F.J., López R., Warren C.R.: Implications of the mesophyll conductance to $\mathrm{CO}_{2}$ for photosynthesis and water use efficiency during long-term water stress and recovery in two contrasting Eucalyptus species. - Plant Cell Environ. 37: 2470-2490, 2014

Cano F.J., Sánchez-Gómez D., Rodríguez-Calcerrada J. et al.: Effects of drought on mesophyll conductance and photosynthetic limitations at different tree canopy layers. - Plant Cell Environ. 36: 1961-1980, 2013.

Chaves M.M.: Effects of water deficits on carbon assimilation. J. Exp. Bot. 42: 1-16, 1991.

Cornic G., Massacci A.: Leaf photosynthesis under drought stress. - In: Baker N.R. (ed.): Photosynthesis and the Environment. Advances in Photosynthesis and Respiration. Pp. 347-366. Springer, Dordrecht 1996.

Dore M.H.I.: Climate change and changes in global precipitation patterns: What do we know? - Environ. Int. 31: 1167-1181, 2005.

Duan B., Li Y., Zhang X.L. et al.: Water deficit affects mesophyll limitation of leaves more strongly in sun than in shade in two contrasting Picea asperata populations. - Tree Physiol. 29: 1551-1561, 2010.

Ennahli S., Earl H.J.: Physiological limitations to photosynthetic carbon assimilation in cotton under water stress. - Crop Sci. 45: 2374-2382, 2005

Epron D., Dreyer E.: Long-term effects of drought on photosynthesis of adult oak trees (Quercus petraea (Matt.) Liebl. \& Quercus robur L.) in a natural stand. - New Phytol. 125: 381-389, 1993.

Flexas J., Barón M., Bota J. et al.: Photosynthesis limitations during water stress acclimation and recovery in the drought-adapted Vitis hybrid Richter-110 ( $V$. berlandieri $\times$ V. rupestris). - J. Exp. Bot. 60: 2361-2377, 2009.

Flexas J., Bota J., Escalona J.M. et al.: Effects of drought on photosynthesis in grapevines under field conditions: an evaluation of stomatal and mesophyll limitations. - Funct. Plant Biol. 29: 461-471, 2002.

Flexas J., Cano F.J., Carriquí M. et al.: $\mathrm{CO}_{2}$ diffusion inside photosynthetic organs. - In: Adams III W.W., Terashima I. (ed.): The Leaf: A Platform for Performing Photosynthesis and Feeding the Plant. Advances in Photosynthesis and 
Respiration. Vol. 44. Pp. 163-208. Springer, Cham 2018.

Flexas J., Niinemets Ü., Gallé A. et al.: Diffusional conductances to $\mathrm{CO}_{2}$ as a target for increasing photosynthesis and photosynthetic water-use efficiency. - Photosynth. Res. 17: 45-59, 2013.

Flexas J., Ribas-Carbó M., Bota J. et al.: Decreased Rubisco activity during water stress is not induced by decreased relative water content but related to conditions of low stomatal conductance and chloroplast $\mathrm{CO}_{2}$ concentration. New Phytol. 172: 73-82, 2006.

Galle A., Florez-Sarasa I., Tomas M. et al.: The role of mesophyll conductance during water stress and rewatering in tobacco (Nicotiana sylvestris): acclimation or limitation? - J. Exp. Bot. 60: 2379-2390, 2009.

Galmés J., Medrano H., Flexas J.: Photosynthesis limitations in response to water stress and rewatering in Mediterranean plants with different growth forms. - New Phytol. 175: 81-93, 2007.

Genty B., Briantais J.-M., Baker N.R.: The relationship between the quantum yield of photosynthetic electron transport and quenching of chlorophyll fluorescence. - BBA-Gen. Subjects 990: 87-92, 1989.

Grams T.E., Kozovits A.R., Häberle K.H. et al.: Combing $\delta^{13} \mathrm{C}$ and $\delta^{18} \mathrm{O}$ analyses to unravel competition, $\mathrm{CO}_{2}$ and $\mathrm{O}_{3}$ effects on physiological performance of different-aged trees. - Plant Cell Environ. 30: 1023-1034, 2007.

Grassi G., Magnani F.: Stomatal, mesophyll conductance and biochemical limitations to photosynthesis as affected by drought and leaf ontogeny in ash and oak trees. - Plant Cell Environ. 28: 834-849, 2005.

Gunasekera D., Berkowitz G.A.: Heterogenous stomatal closure in response to leaf water deficits is not a universal phenomenon. - Plant Physiol. 98: 660-665, 1992.

Hacke U.G., Sperry J.S.: Limits to xylem refilling under negative pressure in Laurus nobilis and Acer negundo. - Plant Cell Environ. 26: 303-311, 2003.

Han J.M., Lei Z.Y., Zhang Y.J. et al.: Drought-introduced variability of mesophyll conductance in Gossypium and its relationship with leaf anatomy. - Physiol. Plantarum 166: 873-887, 2019.

Han J.M., Meng H.F., Wang S.Y. et al.: Variability of mesophyll conductance and its relationship with water use efficiency in cotton leaves under drought pretreatment. - J. Plant Physiol. 194: 61-71, 2016.

Harley P.C., Loreto F., Di Marco G., Sharkey T.D.: Theoretical considerations when estimating the mesophyll conductance to $\mathrm{CO}_{2}$ flux by analysis of the response of photosynthesis to $\mathrm{CO}_{2}$. - Plant Physiol. 98: 1429-1436, 1992.

Hommel R., Siegwolf R., Saurer M. et al.: Drought response of mesophyll conductance in forest understory species - impacts on water-use efficiency and interactions with leaf water movement. - Physiol. Plantarum 152: 98-114, 2014.

IPCC 2013: Climate change 2013: The Physical Science Basis. An overview of the Working Group 1 contribution to the Fifth Assessment Report of the Intergovernmental Panel on Climate Change (IPCC). Pp. 1535. Cambridge University Press, Cambridge 2013.

Joos F., Spahni R.E.: Rates of change in natural and anthropogenic radiative forcing over the past 20,000 years. - P. Natl. Acad. Sci. USA 105: 1425-1430, 2008.

Kubiskem M.E., Abrams M.D.: Stomatal and non-stomatal limitations of photosynthesis in 19 temperate tree species on contrasting sites during wet and dry years. - Plant Cell Environ. 16: 1123-1129, 1993.

Lawlor D.W.: The effects of water deficit on photosynthesis. In: Smirnoff N. (ed.): Environment and Plant Metabolism.
Flexibility and Acclimation. Pp. 129-160. BIOS Scientific Publishers, Oxford 1995.

Loriaux S.D., Avenson T.J., Welles J.M. et al.: Closing in on maximum yield of chlorophyll fluorescence using a single multiphase flash of sub-saturating intensity. - Plant Cell Environ. 36: 1755-1770, 2013.

Luterbacher J., Dietrich D., Xoplaki E. et al.: European seasonal and annual temperature variability, trends, and extremes since 1500. - Science 303: 1499-1503, 2004.

Medrano H., Escalona J.M., Bota J. et al.: Regulation of photosynthesis of $\mathrm{C}_{3}$ plants in response to processive drought: Stomatal conductance as a reference parameter. - Ann. Bot.London 89: 895-905, 2002.

Nadal M., Flexas J.: Variation in photosynthetic characteristics with growth form in a water-limited scenario: Implications for assimilation rates and water use efficiency in crops. - Agr. Water Manage. 216: 457-472, 2019.

Nemani R.R., Keeling C.D., Hashimoto H. et al.: Climate-driven increases in global terrestrial net primary production from 1982 to 1999. - Science 300: 1560-1563, 2003.

Niinemets Ü., Wright I.J., Evans J.R.: Leaf mesophyll diffusion conductance in 35 Australian sclerophylls covering a broad range of foliage structural and physiological variation. J. Exp. Bot. 60: 2433-2449, 2009.

Osmond C.B., Björkman O., Anderson D.J.: Physiological processes in plant ecology. Towards a synthesis with Atriplex. Pp. 468. Springer, Berlin-Heidelberg 1980.

Peguero-Pina J.J., Mendoza-Herrer Ó., Gil-Pelegrín E., SanchoKnapik D.: Cavitation limits the recovery of gas exchange after severe drought stress in holm oak (Quercus ilex L.). Forests 9: 443, 2018b.

Peguero-Pina J.J., Sisó S., Flexas J. et al:: Coordinated modifications in mesophyll conductance, photosynthetic potentials and leaf nitrogen contribute to explain the large variation in foliage net assimilation rates across Quercus ilex provenances. - Tree Physiol. 37: 1084-1094, 2018 a.

Perez-Martin A., Michelazzo C., Torres-Ruiz J.M. et al:: Regulation of photosynthesis and stomatal and mesophyll conductance under water stress and rewatering in olive trees: correlation with gene expression of carbonic anhydrase and aquaporins. - J. Exp. Bot. 65: 3143-3156, 2014.

Perez-Martin A., Torres-Ruiz J.M., Fernández J.E. et al.: Physiological and genetic response of olive leaves to water stress and recovery: implications of mesophyll conductance and genetic expression of aquaporins and carbonic anhydrase. - Acta Hortic. 922: 99-105, 2011.

Pirzad A., Mohammadzadeh S.: Water use efficiency of three mycorrhizal Lamiaceae species (Lavandula officinalis, Rosmarinus officinalis and Thymus vulgaris). - Agr. Water Manage. 204: 1-10, 2018.

Resco V., Ewers B.E., Sun W. et al.: Drought-induced hydraulic limitations constrain leaf gas exchange recovery after precipitation pulses in the $\mathrm{C}_{3}$ woody legume, Prosopis velutina. - New Phytol. 181: 672-682, 2009.

Rho H., Yu D.J., Kim S.J., Lee H.J.: Limitation factors for photosynthesis in 'Bluecrop' highbush blueberry (Vaccinium corymbosum) leaves in response to moderate water stress. J. Plant Biol. 55: 450-457, 2012.

Shatil-Cohen A., Attia Z., Moshelion M.: Bundle-sheath cell regulation of xylem-mesophyll water transport via aquaporins under drought stress: a target of xylem-borne ABA? - Plant J. 67: 72-80, 2011.

Sun J.W., Guan D.X., Wu J.B. et al.: Day and night respiration of three tree species in a temperate forest of northeastern China. - iForest 8: 25-32, 2015.

Tezara W., Mitchell V.J., Driscoll S.D., Lawlor D.W.: Water 
stress inhibits plant photosynthesis by decreasing coupling factor and ATP. - Nature 401: 914-917, 1999.

Tomás M., Medrano H., Brugnoli E. et al.: Variability of mesophyll conductance in grapevine cultivars under water stress conditions in relation to leaf anatomy and water use efficiency. - Aust. J. Grape Wine Res. 20: 272-280, 2014.

Valentini R., Epron D., De Angelis P. et al.: In situ estimation of net $\mathrm{CO}_{2}$ assimilation, photosynthetic electron flow and photorespiration in Turkey oak (Q. cerris L.) leaves: diurnal cycles under different levels of water supply. - Plant Cell Environ. 18: 631-640, 1995.

Wang X.X., Du T.T., Huang J.L. et al.: Leaf hydraulic vulnerability triggers the decline in stomatal and mesophyll conductance during drought in rice. - J. Exp. Bot. 69: 40334045, 2018.

Warren C.R., Aranda I., Cano F.J.: Responses to water stress of gas exchange and metabolites in Eucalyptus and Acacia spp. Plant Cell Environ. 34: 1609-1629, 2011.

Xia J., Zhao X.M., Ren J.Y. et al.: Photosynthetic and water physiological characteristics of Tamarix chinensis under different groundwater salinity conditions. - Environ. Exp. Bot. 138: 173-183, 2017.
Xiong D.L., Liu X., Liu L.M. et al.: Rapid responses of mesophyll conductance to changes of $\mathrm{CO}_{2}$ concentration, temperature and irradiance are affected by $\mathrm{N}$ supplements in rice. - Plant Cell Environ. 38: 2541-2550, 2015a.

Xiong D.L., Yu T.T., Zhang T. et al.: Leaf hydraulic conductance is coordinated with leaf morpho-anatomical traits and nitrogen status in the genus Oryza. - J. Exp. Bot. 66: 741-748, 2015 b.

Zhang H.X., McDowell N.G., Adams H.D. et al.: Divergences in hydraulic conductance and anatomical traits of stems and leaves in three temperate tree species coping with drought, $\mathrm{N}$ addition and their interactions. - Tree Physiol. 40: 230-244, 2020.

Zhou S.X., Medlyn B., Sabaté S. et al.: Short-term water stress impacts on stomatal, mesophyll and biochemical limitations to photosynthesis differ consistently among tree species from contrasting climates. - Tree Physiol. 34: 1035-1046, 2014.

Zhu K., Yuan F.H., Wang A.Z. et al.: Effects of soil rewatering on mesophyll and stomatal conductance and the associated mechanisms involving leaf anatomy and some physiological activities in Manchurian ash and Mongolian oak in the Changbai Mountains. - Plant Physiol. Bioch. 144: 22-34, 2019.

(C) The authors. This is an open access article distributed under the terms of the Creative Commons BY-NC-ND Licence. 